\title{
Timing of treatment interruption among latently infected tuberculosis cases treated with a nine-month course of daily isoniazid: findings from a time to event analysis
}

Marie Nancy Séraphin ${ }^{1,2^{*}}$ (D, HsiaoChu Hsu ${ }^{1,2}$, Helena J. Chapman ${ }^{1,2}$, Joanne L. de Andrade Bezerra ${ }^{1,2}$, Lori Johnston ${ }^{3}$, Yang Yang ${ }^{2,4}$ and Michael Lauzardo ${ }^{1,2}$

\begin{abstract}
Background: Treatment of latent tuberculosis infection (LTBI) in high-risk groups is an effective strategy for TB control and elimination in low incidence settings. A nine-month course of daily isoniazid (INH) has been the longest prescribed therapy; however, completion rates are suboptimal. We need data to guide TB program outreach efforts to optimize LTBI treatment completion rates.
\end{abstract}

Methods: We pooled seven (2009-2015) years of LTBI treatment outcome data. We computed the probability of INH treatment disruption over time by patient demographic and clinical risk factors. We used log-rank tests and Cox proportional hazards models to assess the risk factors for treatment disruption.

Results: We analyzed data from 12,495 persons with complete data on INH treatment initiation. Pediatric cases (0-17 years), recent contacts of active TB patients, and non-U.S.-born adults living in the United States $\leq 5$ years represented 25.2, 13.0, and $59.2 \%$ of the study population, respectively. Overall, $48.4 \%$ failed to complete therapy. The median treatment duration was 306 days (95\% Cl: 297, 315). A significant drop in adherence could be observed around day 30 of treatment initiation. Indeed, by day 30 of treatment, $17.0 \%$ ( $95 \% \mathrm{Cl}: 16.4,17.7)$ of patients had defaulted on therapy. Pediatric patients ( $\mathrm{HR}=0.83,95 \% \mathrm{Cl}$ : $0.78,0.89)$, recent contacts $(H R=0.74,95 \% \mathrm{Cl}: 0.68,0.81)$, patients with diabetes ( $\mathrm{HR}=0.77,95 \% \mathrm{Cl}: 0.60,0.98)$, and patients with HIV (HR=0.39, 95\% Cl: 0.30, 0.51) had a lower risk of treatment default. However, black patients ( $H R=1.57,95 \%$ Cl: 1.44, 1.70), Hispanic patients ( $H R=1.54,95 \% \mathrm{Cl}: 1.43,1.66)$, and non-U.S.-born persons living in the United States $\leq 5$ years $(H R=$ $1.25,95 \%$ Cl: $1.18,1.32)$ were significantly more likely to default on therapy.

Conclusions: In this analysis of INH treatment outcome, we see high levels of treatment discontinuation. On average, patients defaulted on their prescribed nine-month daily INH therapy within 30 days of initiating treatment, and those at increased risk of progression to active disease were most likely to do so. We highlight the need to introduce patientcentered programs to increase treatment adherence in this population.

Keywords: Latent tuberculosis infection, Prevention, Treatment outcomes

\footnotetext{
* Correspondence: nseraphin@ufl.edu

'Division of Infectious Diseases and Global Medicine, Department of

Medicine, University of Florida, 2055 Mowry Road, Suite 250, Gainesville, FL

32611, USA

${ }^{2}$ Emerging Pathogens Institute, University of Florida, 2055 Mowry Road,

Gainesville, FL 32610, USA

Full list of author information is available at the end of the article
}

(c) The Author(s). 2019 Open Access This article is distributed under the terms of the Creative Commons Attribution 4.0 International License (http://creativecommons.org/licenses/by/4.0/), which permits unrestricted use, distribution, and reproduction in any medium, provided you give appropriate credit to the original author(s) and the source, provide a link to the Creative Commons license, and indicate if changes were made. The Creative Commons Public Domain Dedication waiver (http://creativecommons.org/publicdomain/zero/1.0/) applies to the data made available in this article, unless otherwise stated. 


\section{Background}

In low tuberculosis (TB) incidence countries like the United States (U.S.), early identification and treatment of persons with asymptomatic or latent Mycobacterium tuberculosis infection (LTBI) are fundamental for sustainable prevention and control efforts toward TB elimination $(<1$ TB case / 1 million population) [1]. This indispensable approach is in light of an estimated one-third of the global population infected with $M$. tuberculosis, who face a 5 to $10 \%$ risk of progression to active TB disease during their lifespan [2]. By identifying populations at high-risk for TB disease - such as recent contacts, diabetics, or persons with immunosuppression [e.g., human immunodeficiency virus (HIV) / acquired immunodeficiency syndrome (AIDS), dialysis or organ transplant recipients, selected pharmacological agents] - targeted LTBI diagnostic testing and clinical evaluation can lead to the most effective treatment regimen, thus reducing risk of TB disease [3]. These concerted efforts for prompt LTBI diagnosis and effective treatment have the potential to reduce global TB incidence rates, curb transmission, and ultimately reach the targets of the World Health Organization's End TB Strategy (2016-2035) [4]. In the U.S., TB incidence has decreased over the past two decades, leading to current incidence rates that lie above the TB elimination threshold of one TB case per million person per year [5]. In 2017, 9,093 new TB cases (2.9 cases / 100,000 population) were reported [6, 7]. The incidence among persons born outside of the U.S. was $14.6 / 100,100$ population, compared to $1.0 / 100,000$ among the U.S.-born population [6]. However, risk factors associated with TB reactivation in high-risk population groups, remain a significant challenge for continued TB elimination efforts. Previous studies concluded that an estimated $93 \%$ of foreign-born persons diagnosed with active TB disease were due to TB reactivation [8]. Hence, with 13 million U.S. residents estimated to have LTBI, this high-risk population group should be prioritized for diagnostic testing and prophylaxis treatment [9].

Isoniazid (INH) was the first anti-tuberculosis drug recommended for LTBI treatment, a decision supported by findings from several randomized clinical trials conducted in the 1960s $[10,11]$. Although a prescribed nine-month INH regimen is preferred and considered more efficacious, a sixmonth INH regimen can be alternatively prescribed to improve patient adherence [12]. INH selectively inhibits the cytochrome P450 enzymes of $M$. tuberculosis and is noted for its narrow spectrum of action for mycobacteria species and high bactericidal activity [13]. Aside from the benefits of INH monotherapy for LTBI management, there are reported drawbacks such as extended treatment duration, additional health care costs, potential toxicities, and risk of INH monoresistance [14-16]. Serious adverse effects can contribute to patient treatment non-compliance and potential INH discontinuation, including hepatotoxicity risk estimated between 1 and 4\%, occurring within the first few months after treatment initiation $[17,18]$. Peripheral neuropathy-which can be prevented with vitamin B6 (pyridoxine) supplementation-as well as dermatitis and lupus-like syndrome are other INH adverse effects [19].

Acceptance and completion of LTBI treatment, based on the total number of administered doses taken, continue to be a hurdle in clinical practice. In many TB programs throughout the U.S., including Florida, the ninemonth course of INH for LTBI therapy is self-administered. Patients are given enough drugs for a month and are required to go back to the health center for monthly evaluation of side effects and refills. Previous studies have reported several predictors of acceptance of LTBI treatment among patients, including an understanding of LTBI and their ability to transmit active TB disease to their close contacts, convenient scheduling for medical appointment and supportive staff, and low acculturation [20]. On the other hand, risk factors associated with LTBI treatment default or discontinuation have included severe side effects, unemployment, and limited social support $[21,22]$. Non-adherence rates $(<80 \%$ of prescribed dose regimen) range from 31 to $53 \%$ [15, 17, 2325]. However, limited data exist on the timing of treatment discontinuation, which are important to the design of interventions to increase overall adherence to therapy. In this study, we investigated the timing of INH treatment defaults and associated risk factors to guide TB program outreach efforts to meet the specific needs of diverse patient populations, optimize LTBI treatment completion, and reduce risk of $\mathrm{TB}$ reactivation.

\section{Methods}

\section{Study population}

Data from a LTBI treatment registry collected from 2009 to 2015 were pooled for these analyses. Persons with LTBI were diagnosed and locally managed by the 67 different county health departments in Florida, and the Florida Department of Health TB Control Program centrally pooled the data. LTBI diagnosis was based on either a positive tuberculosis skin test (TST) and/or interferon gamma release assay (IGRA) test followed by a medical evaluation and additional testing consisting of chest $\mathrm{x}$-ray and, in some cases, an acidfast sputum smear examination to rule out active TB disease. We included everyone initiated on INH in the analysis. Patients were prescribed self-administered INH $300 \mathrm{mg}$ per $\mathrm{kg}$ body weight daily, for 9 months. Drugs were dispensed during scheduled monthly visits to the health department LTBI clinic. LTBI is not a reportable condition in Florida. As such, these data only capture people diagnosed and managed by county health departments' TB clinics in Florida.

\section{Treatment outcomes and censoring}

All treatment outcomes were available within the registry and recorded at the health department level by a 
provider involved in the care of the LTBI client. We determined the duration of treatment by calculating the number of days between the date of treatment initiation and the date of treatment termination. We excluded from the analyses patients with a treatment plan that was open for longer than 12 months as well as patients who completed therapy in less than 6 months. Based on treatment outcomes, patients were classified into five groups: treatment completed, loss to follow-up, chose to stop, adverse reactions, and dead. We treated loss to follow-up and chose to stop as observed default events. The other outcomes were right-censored. Data on patients' gender, race, HIV status, diabetes status, and other immunosuppressive conditions collected at baseline were also included in the analyses to evaluate predictors for treatment disruption.

\section{Statistical analysis}

We conducted all analyses using the Statistical Analysis System (SAS) version 9.4 and the $\mathrm{R}$ programming language version 3.6.0. We computed the probability of INH treatment disruption over time for each of the demographic and clinical risk factor variables and displayed those using Kaplan-Meier curves. To compare the time to treatment interruption for each level of our covariates, we used log-rank with log-log transformation for the pointwise confidence bounds. Statistical significance was assessed at the level of 0.05 . We computed univariate and multivariable hazard ratio with the 95\% confidence intervals (CI) of treatment disruption using Cox proportional hazards models. We visually assessed the assumption of proportionality of hazards for our Cox models by inspecting the group-based empirical cumulative hazard curves for extreme non-proportionality and none of the covariates included in the analyses violated this assumption (see Additional file 1: Figure S1). We used Efron correction to account for ties in the treatment disruption time.

\section{Results}

Overall, 18,294 persons had a positive TST and/or IGRA test results with a diagnosis of LTBI over the study

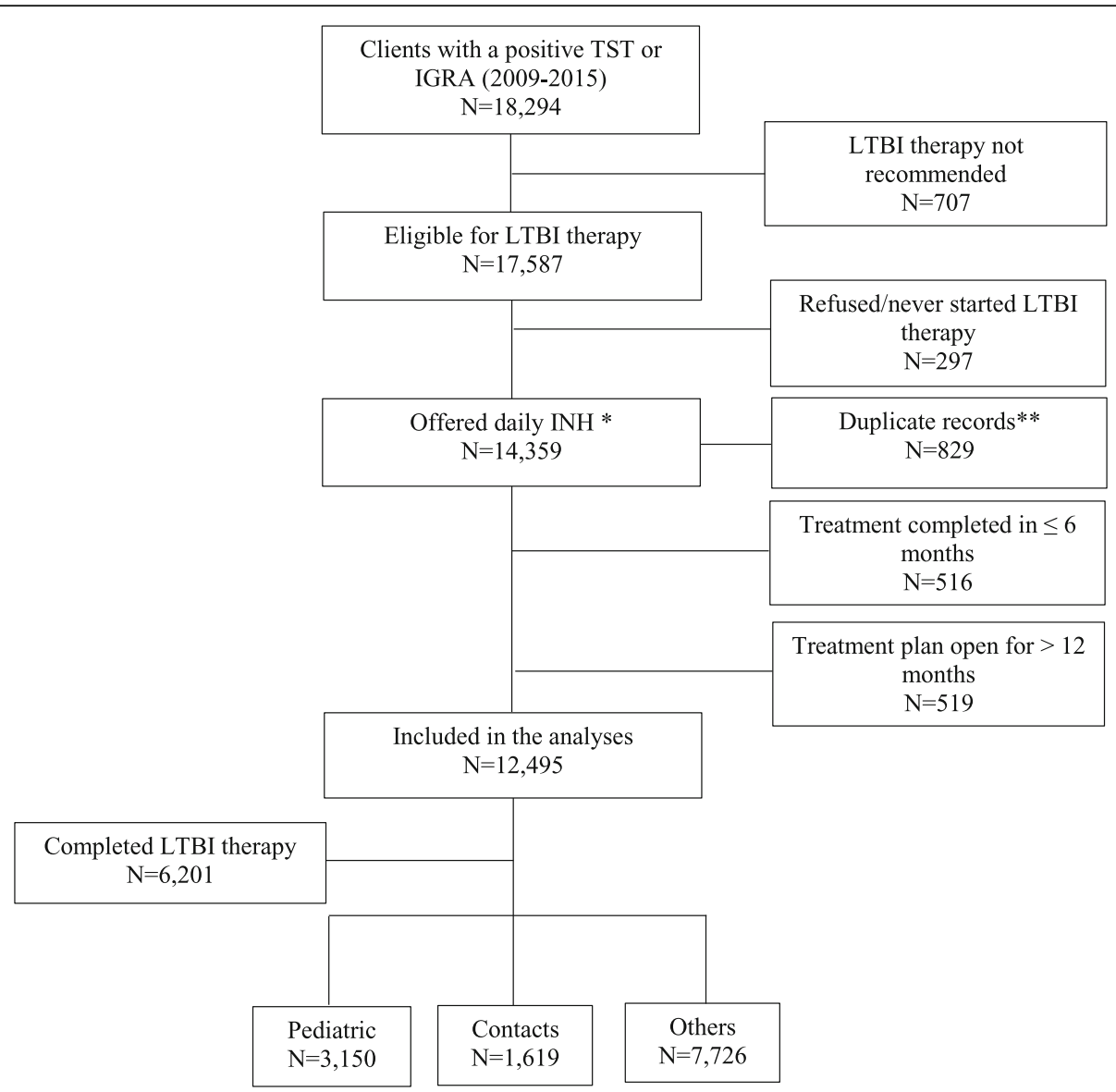

Fig. 1 Flow diagram detailing selection of cases included in the analyses. TST indicates tuberculin skin test; IGRA indicates interferon gamma release assay; LTBI indicates latent tuberculosis infection; INH indicates Isoniazid. * Others were offered either three months of isoniazid and rifapentine (3HP) or four months of rifampin (4R) ** Includes 28 observations where all demographic and clinical data were the same but treatment outcome differed 
period (Fig. 1). Individuals who were not a candidate for LTBI therapy; i.e. those with a history of TB or LTBI treatment, or pregnant; were excluded from the analyses $(n=707)$. We excluded individuals who refused or never initiated therapy $(n=297)$. We also excluded persons who completed therapy in less than 6 months $(n=516)$, persons with duplicate case IDs $(n=829)$, and patients with a care plan that had been opened for longer than 12 months $(n=519)$. About half of the individuals in this group ultimately completed therapy $(n=333)$; however, not finishing within 12 months is more or less a type of default, which does not fit in the definition of default we focused on this study. In Additional file 1, we show a distribution of the treatment duration data by the different outcomes after (Additional file 1 Figure S2A) and before (Additional file 1Figure S2B). We noticed that the overall time distribution of the treatment outcomes did change. In addition, including these cases as a sensitivity analysis did not change the overall study findings (Additional file 1: Figure S3). This leads us to conclude that the excluded observations were more likely outliers and data recording errors that did not significantly bias the overall study sample.

Table 1 shows the characteristics of the LTBI patients included in our study, stratified by their treatment outcomes. Of the 12,495 patients, $25.2 \%$ were pediatric cases (0-17 years), $13.0 \%$ were recent contacts to an infectious TB case, and $61.8 \%$ were other adults, the majority of which were non-U.S.-born persons (60.4\%). Overall, the majority of our study sample composed of non-U.S-born persons who had immigrated within the last 5 years $(52.2 \%)$ and non-Hispanic patients (54.5\%). The racial composition of the sample was $36.0 \%$ White, 34.1\% Black/African American, and 7.5\% Asian. About 2 $\%$ were HIV co-infected at the time of diagnosis, $1.3 \%$ were diabetic, and less than $1.0 \%$ had one or more other immunosuppressive conditions.

Table 1 Characteristics of persons with latent tuberculosis infection who initiated INH monotherapy and followed for twelve months

\begin{tabular}{|c|c|c|c|c|c|c|c|}
\hline $\begin{array}{l}\text { Predictors } \\
(N=12,495)\end{array}$ & $\begin{array}{l}\text { Sample } \\
\text { N (\%) }\end{array}$ & $\begin{array}{l}\text { Treatment Completed } \\
\mathrm{N}(\%)\end{array}$ & $\begin{array}{l}\text { Loss to Follow } \\
N(\%)\end{array}$ & $\begin{array}{l}\text { Chose to Stop } \\
N(\%)\end{array}$ & $\begin{array}{l}\text { Adverse Reaction } \\
\text { N (\%) }\end{array}$ & $\begin{array}{l}\text { Died } \\
\text { N (\%) }\end{array}$ & $p$-value \\
\hline & & $6201(49.6)$ & $3120(25.0)$ & $2928(23.4)$ & $237(1.9)$ & $9(0.1)$ & \\
\hline \multicolumn{8}{|l|}{ Type of Patients } \\
\hline $\begin{array}{l}\text { Pediatric } \\
\text { Recent Contact } \\
\text { Other Adults }\end{array}$ & $\begin{array}{l}3150(25.2) \\
1619(13.0) \\
7726(61.8)\end{array}$ & $\begin{array}{l}1639(52.0) \\
901(55.6) \\
3661(47.4)\end{array}$ & $\begin{array}{l}823(26.1) \\
382(23.6) \\
1915(24.8)\end{array}$ & $\begin{array}{l}635(20.2) \\
310(19.1) \\
1983(25.7)\end{array}$ & $\begin{array}{l}53(1.7) \\
25(1.5) \\
159(2.1)\end{array}$ & $\begin{array}{l}- \\
1(0.1) \\
8(0.1)\end{array}$ & $<.0001$ \\
\hline \multicolumn{8}{|l|}{ Gender } \\
\hline $\begin{array}{l}\text { Female } \\
\text { Male } \\
\text { Missing }\end{array}$ & $\begin{array}{l}6076(48.6) \\
6417(51.4) \\
2(0.0)\end{array}$ & $\begin{array}{l}3090(50.9) \\
3111(48.5) \\
-\end{array}$ & $\begin{array}{l}1433(23.6) \\
1685(26.3) \\
2(100.0)\end{array}$ & $\begin{array}{l}1400(23.0) \\
1528(23.8) \\
-\end{array}$ & $\begin{array}{l}150(2.5) \\
87(1.4)\end{array}$ & $\begin{array}{l}3(0.0) \\
6(0.1)\end{array}$ & $<.0001$ \\
\hline \multicolumn{8}{|l|}{ Ethnicity } \\
\hline $\begin{array}{l}\text { Non-Hispanic } \\
\text { Hispanic } \\
\text { Unknown }\end{array}$ & $\begin{array}{l}6808(54.5) \\
5513(44.1) \\
174(1.4)\end{array}$ & $\begin{array}{l}3714(54.5) \\
2394(43.4) \\
93(53.4)\end{array}$ & $\begin{array}{l}1881(27.6) \\
1189(21.6) \\
50(28.7)\end{array}$ & $\begin{array}{l}1093(16.0) \\
1807(32.8) \\
28(16.1)\end{array}$ & $\begin{array}{l}114(1.7) \\
120(2.2) \\
3(1.7)\end{array}$ & $\begin{array}{l}6(0.1) \\
3(0.0) \\
-\end{array}$ & $<.0001$ \\
\hline \multicolumn{8}{|l|}{ Race } \\
\hline $\begin{array}{l}\text { White } \\
\text { Black } \\
\text { Asian } \\
\text { Other }\end{array}$ & $\begin{array}{l}4496(36.0) \\
4261(34.1) \\
932(7.5) \\
2806(22.5)\end{array}$ & $\begin{array}{l}2027(45.1) \\
2035(47.8) \\
650(69.7) \\
1489(53.1)\end{array}$ & $\begin{array}{l}1004(45.1) \\
1328(47.8) \\
194(20.8) \\
594(21.2)\end{array}$ & $\begin{array}{l}1350(30.0) \\
833(19.5) \\
80(8.6) \\
665(23.7)\end{array}$ & $\begin{array}{l}110(2.4) \\
63(1.5) \\
7(0.7) \\
57(2.0)\end{array}$ & $\begin{array}{l}5(0.1) \\
2(0.0) \\
1(0.1) \\
1(0.0)\end{array}$ & $<.0001$ \\
\hline \multicolumn{8}{|l|}{ Birth Origin } \\
\hline $\begin{array}{l}\text { U.S.-born } \\
\text { Non-U.S.-born, } \leq 5 \text { Years } \\
\text { Non-U.S.-born, > } 5 \text { Years }\end{array}$ & $\begin{array}{l}5097(40.8) \\
6517(52.2) \\
881(7.0)\end{array}$ & $\begin{array}{l}2780(54.5) \\
2998(46.0) \\
423(48.0)\end{array}$ & $\begin{array}{l}1325(26.0) \\
1591(24.4) \\
204(23.2)\end{array}$ & $\begin{array}{l}890(17.5) \\
1802(27.6) \\
236(26.8)\end{array}$ & $\begin{array}{l}96(1.9) \\
124(1.9) \\
17(1.9)\end{array}$ & $\begin{array}{l}6(0.1) \\
2(0.0) \\
1(0.1)\end{array}$ & $<.0001$ \\
\hline \multicolumn{8}{|l|}{ HIV Co-infected } \\
\hline $\begin{array}{l}\text { No } \\
\text { Yes }\end{array}$ & $\begin{array}{l}12,275(98.2) \\
220(1.8)\end{array}$ & $\begin{array}{l}6038(49.2) \\
163(74.1)\end{array}$ & $\begin{array}{l}3087(25.1) \\
33(15.0)\end{array}$ & $\begin{array}{l}2907(23.7) \\
21(9.5)\end{array}$ & $\begin{array}{l}236(1.9) \\
1(0.4)\end{array}$ & $\begin{array}{l}7(0.1) \\
2(0.9)\end{array}$ & $<.0001$ \\
\hline \multicolumn{8}{|l|}{ Diabetic } \\
\hline $\begin{array}{l}\text { No } \\
\text { Yes }\end{array}$ & $\begin{array}{l}12,512(98.2) \\
170(1.3)\end{array}$ & $\begin{array}{l}6099(49.5) \\
102(60.4)\end{array}$ & $\begin{array}{l}3079(25.0) \\
41(24.3)\end{array}$ & $\begin{array}{l}2906(23.6) \\
22(13.0)\end{array}$ & $\begin{array}{l}234(1.9) \\
3(1.8)\end{array}$ & $\begin{array}{l}8(0.1) \\
1(0.6)\end{array}$ & 0.0010 \\
\hline \multicolumn{8}{|c|}{ Other Immunosuppressive Conditions* } \\
\hline $\begin{array}{l}\text { No } \\
\text { Yes }\end{array}$ & $\begin{array}{l}12,395(99.2) \\
100(0.8)\end{array}$ & $\begin{array}{l}6136(49.5) \\
65(65.0)\end{array}$ & $\begin{array}{l}3104(25.0) \\
16(16.0)\end{array}$ & $\begin{array}{l}2913(23.5) \\
15(15.0)\end{array}$ & $\begin{array}{l}235(1.9) \\
2(2.0)\end{array}$ & $\begin{array}{l}7(0.1) \\
2(2.0)\end{array}$ & $<.0001$ \\
\hline
\end{tabular}

Notes: ${ }^{*}$ includes individuals with hematologic disorders $(n=6)$, chronic renal failure $(n=21)$, non-HIV related immunosuppressive conditions $(n=48)$, and those on corticosteroid therapy $(n=21)$ 
Overall, $48.4 \%$ of the sample failed to complete their nine-month INH treatment regimen; about $2 \%(n=237)$ experienced an adverse reaction to the treatment and $0.1 \%(n=9)$ died. While a quarter of the cases were lost to follow up, another quarter $(23.4 \%)$ chose to stop therapy (Table 1). The median treatment duration was 306 days (95\% CI: 297, 315). Median INH treatment duration was 325 days (95\% CI: 313-335) days for pediatric cases, 344 (322-356) days for recent contacts, and 276 (95\% CI: 258-295) days for other adults.

The baseline cumulative hazard of treatment completion for the whole sample (Additional file 1 Figure S1, panel A) and the sample stratified by patient type (panel B) are presented in Additional file 1. A significant drop in adherence can be observed in the first 30 days of treatment initiation. Indeed, $17.0 \%$ (95\% CI: 16.4-17.7) of patients who initiated therapy had discontinued therapy by day 30 . The ninemonth INH therapy is dispensed at monthly intervals during scheduled visits to the LTBI clinic, suggesting that the first 30 days after treatment initiation are the most vulnerable time point for treatment default and loss to follow-up. We evaluated the probabilities of non-disruption in the first 4 weeks of therapy. Figure 2 shows the probabilities of staying on the nine-month INH therapy, stratified by each of the risk factors evaluated in this study. On average, males had a shorter treatment duration of 293 (95\% CI: 271, 304) days, compared to 318 (95\% CI: 308, 333) days among females. The duration of treatment was also shorter for non-U.S.born, Hispanic, Whites, HIV-negative, patients without diabetes, and patients without an immunosuppressive condition. At 30 days after treatment initiation, $17.9 \%$ (95\% CI: $17.0,18.9)$ of males compared to $16.1 \%$ (95\% CI: 15.2 , 17.0) of females had interrupted their nine-month INH therapy. Similarly, at day 30 of therapy, $21.9 \%$ ( $95 \%$ CI: 20.8 , 23.0) of Hispanic patients had interrupted their nine-month INH therapy, compared to $13.2 \%$ ( $95 \%$ CI: $12.4,14.0)$ of non-Hispanic patients.

The cumulative incidence of INH treatment interruption for Asian patients at day 30 of therapy was $9.7 \%$ (95\% CI: $7.9,11.7$ ), compared to $20.5 \%$ (95\% CI: 19.3, 21.7) among White patients, $16.1 \%$ (95\% CI: 15.0, 17.2) among Black patients, and 15.4\% (95\% CI: 14.1, 16.8) among the other racial groups. By the first month of INH therapy, 20.1\% (95\% CI: 19.2, 21.1) of patients who had recently immigrated to the U.S. ( $\leq 5$ years) had discontinued treatment, compared to $12.9 \%$ (95\% CI: $12.0,21.1)$ in U.S.-born, and $17.9 \%$ (95\% CI: $15.5,20.6)$ in those who immigrated to the U.S. $>5$ years. On the other hand, persons co-infected with HIV [8.2\% (95\% CI: $5.2,12.7)$ versus $17.2 \%(95 \% \mathrm{CI}: 16.5,17.9)]$, those with diabetes [15.4\% (95\% CI: 10.8, 21.8) versus $17.1 \%$ (95\% CI: 16.4, $17.8)]$, and one or more other immunosuppressive conditions [14.0\% (95\% CI: 8.5, 22.5) versus $17.4 \%$ (95\% CI: 16.4, 17.7)] had a lower cumulative incidence of treatment interruption at 4 weeks.

The univariate and multivariable hazard ratios for treatment disruption are presented in Table 2. Pediatric patients ( $\mathrm{HR}=0.83,95 \% \mathrm{CI}: 0.78,0.89)$ and recent contacts (HR $=0.74,95 \%$ CI: $0.68,0.81)$ had a significantly lower risk of treatment interruption compared to other adults. The risk of treatment interruption was also lower

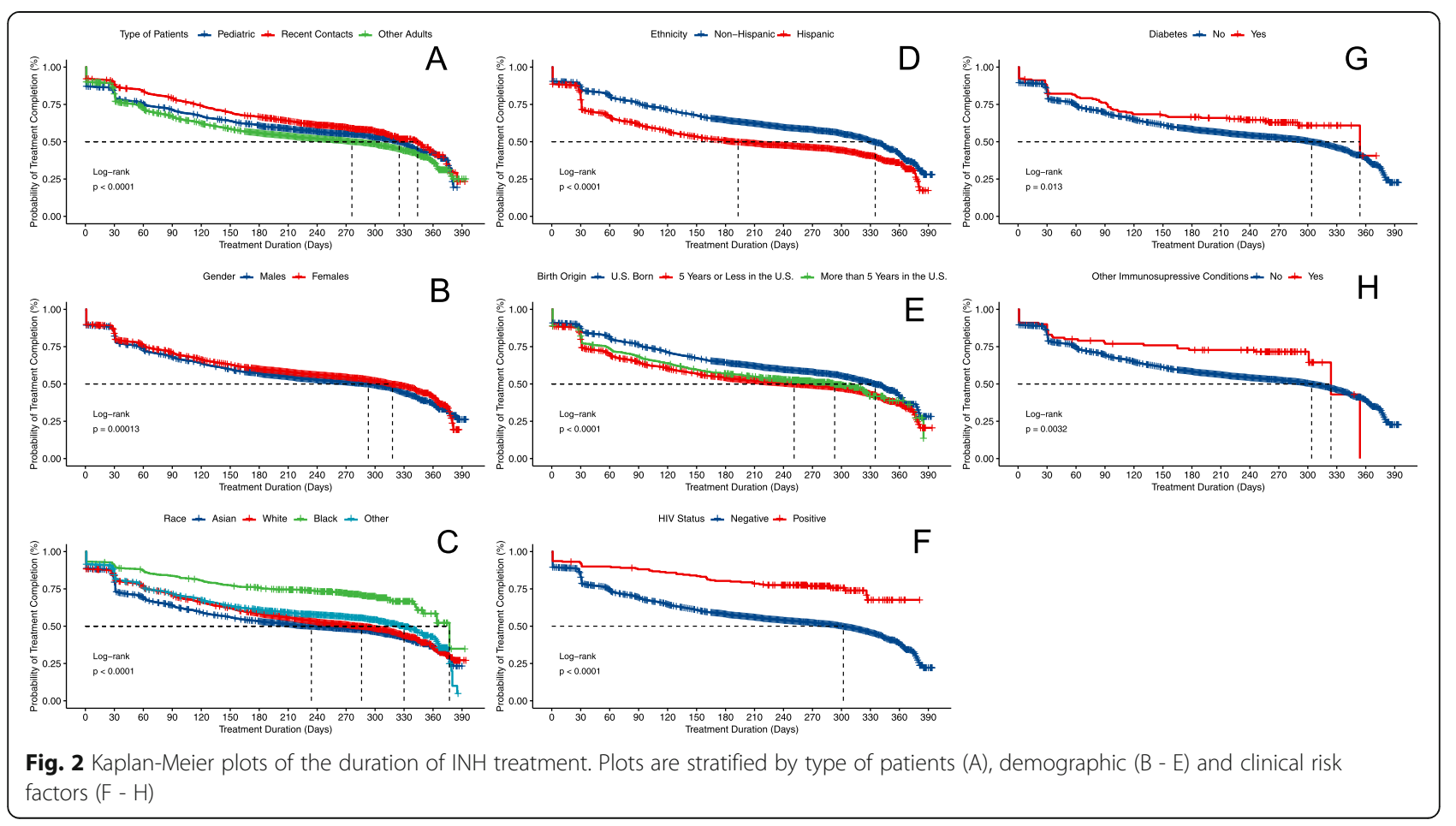


for female patients $(\mathrm{HR}=0.90,95 \% \mathrm{CI}$ : 0.85, 0.94), Asian patients ( $\mathrm{HR}=0.77,95 \% \mathrm{CI}: 0.67,0.89)$, those co-infected with $\mathrm{HIV}(\mathrm{HR}=0.39,95 \% \mathrm{CI}$ : 0.30, 0.51), diabetic patients $(\mathrm{HR}=0.77,95 \% \mathrm{CI}: 0.60,0.98)$, and those with one or more immunosuppressive conditions $(\mathrm{HR}=0.65,95 \% \mathrm{CI}$ : 0.46 , $0.93)$. On the other hand, the risk was significantly higher for White patients ( $\mathrm{HR}=1.26,95 \% \mathrm{CI}: 1.18,1.36)$ and Black patients ( $\mathrm{HR}=1.57,95 \% \mathrm{CI}: 1.44,1.70)$ compared to other racial groups; for non-U.S.-born individuals who immigrated $\leq 5$ years $(\mathrm{HR}=1.25,95 \% \mathrm{CI}: 1.18,1.32)$ compared to U.S.-born patients; and Hispanic patients $(\mathrm{HR}=1.54,95 \%$ CI: $1.43,1.66)$ compared to non-Hispanic patients.

Table 2 Risk Factors for isoniazid treatment interruptions among latent tuberculosis cases followed for 12 months

\begin{tabular}{|c|c|c|}
\hline Predictors & $\begin{array}{l}\text { Unadjusted } \\
\text { HR }(95 \% \mathrm{Cl})\end{array}$ & $\begin{array}{l}\text { Adjusted } \\
\text { HR ( } 95 \% \text { Cl) }\end{array}$ \\
\hline \multicolumn{3}{|l|}{ Type of Patient } \\
\hline Pediatric & $0.87(0.82,0.93)$ & $0.83(0.78,0.89)$ \\
\hline Recent Contact & $0.74(0.69,0.81)$ & $0.74(0.68,0.81)$ \\
\hline Other Adults & 1.00 & 1.00 \\
\hline \multicolumn{3}{|l|}{ Gender } \\
\hline Male & 1.00 & 1.00 \\
\hline Female & $0.91(0.86,0.95)$ & $0.90(0.85,0.94)$ \\
\hline \multicolumn{3}{|l|}{ Ethnicity } \\
\hline Non-Hispanic & 1.00 & 1.00 \\
\hline Hispanic & $1.46(1.38,1.53)$ & $1.54(1.43,1.66)$ \\
\hline \multicolumn{3}{|l|}{ Race } \\
\hline White & $1.28(1.19,1.37)$ & $1.26(1.18,1.36)$ \\
\hline Black & $1.14(1.06,1.22)$ & $1.57(1.44,1.70)$ \\
\hline Asian & $0.58(0.51,0.66)$ & $0.77(0.67,0.89)$ \\
\hline Other & 1.00 & 1.00 \\
\hline \multicolumn{3}{|l|}{ Birth Origin } \\
\hline U.S.-born & 1.00 & 1.00 \\
\hline Non-U.S.-born, $\leq 5$ Years & $1.34(1.27,1.41)$ & $1.25(1.18,1.32)$ \\
\hline Non-U.S.-born, > 5 Years & $1.24(1.12,1.37)$ & $1.16(1.04,1.29)$ \\
\hline \multicolumn{3}{|l|}{ HIV Co-infected } \\
\hline No & 1.00 & 1.00 \\
\hline Yes & $0.41(0.31,0.53)$ & $0.39(0.30,0.51)$ \\
\hline \multicolumn{3}{|l|}{ Diabetic } \\
\hline No & 1.00 & 1.00 \\
\hline Yes & $0.73(0.57,0.94)$ & $0.77(0.60,0.98)$ \\
\hline
\end{tabular}

Other Immunosuppressive Conditions

\begin{tabular}{lll} 
No & 1.00 & 1.00 \\
Yes & $0.59(0.42,0.85)$ & $0.65(0.46,0.93)$ \\
\hline
\end{tabular}

Notes: HR hazard ratio; * $p$-values are based on the Cox proportional hazards models

\section{Discussion}

It is estimated that 1.7 billion of the world population has LTBI, with a $5-10 \%$ lifetime risk of developing active disease $[26,27]$. This risk is especially elevated for high-risk groups, such as children $<5$ years of age, recent immigrants from high TB burden countries, diabetics, those co-infected with HIV, or those with other non-HIV immunosuppressive conditions [28]. In addition, LTBI reactivation in these groups can drive low TB transmission rates in communities [14, 29]. In the U.S., about 11 million people have LTBI [30]. To have the greatest impact on TB elimination in low incidence settings, studies using mathematical modeling have shown that high-risk groups should be targeted for LTBI diagnosis and treatment [29]. Beyond recent contacts, children $<5$ years old, the immunocompromised, and foreign-born persons from high TB burden countries represent a priority group for TB programs in the U.S. [6]. Foreign-born persons, especially recent arrivals (within $\leq 5$ years of immigration) from high incidence countries, are at high risk of TB reactivation. Studies have shown that most of the disease burden is concentrated within the first 5 years of immigration [31, 32]. $\mathrm{INH}$ is currently the drug of choice for most programs due to its tolerability and established effectiveness [33]. However, INH treatment default is very common and a number of studies have reported risk factors for defaulting, including loss to follow up [34, 35]. In this study, we show that foreign-born, ethnic, and racial minorities are at increased risk of defaulting treatment within the first month of the ninemonth INH therapy. This indicates that a significant number of LTBI cases who accept LTBI treatment and are sent home with their first monthly dose likely never initiate LTBI therapy.

In addition to 9 months of daily INH, other approved LTBI therapy options include 3 months of weekly INH and Rifapentine (3HP) by directly observed therapy (DOT), and 4 months of daily, self-administered Rifampin (4R) [36]. The shorter treatment options have better compliance rates compared to nine-month of daily INH [37]. Nevertheless, non-adherence remains an issue in high-risk groups [34]. Under actual use scenario, $85 \%$ of patients complete $3 \mathrm{HP}$ by DOT and this completion rate is comparable for $4 \mathrm{R}$ [25]. New clinical trials are underway to evaluate the safety and efficacy of even shorter regimens [38]. Beyond shortening duration of LTBI therapy, we should address and evaluate the various reasons why patients discontinue or never initiate LTBI therapy.

Perhaps it is possible to improve LTBI treatment adherence and completion if programs incorporate evidence from the long-term management of other infectious diseases, such as HIV. Some of the facilitators to antiretroviral therapy (ART) adherence outlined in the literature could potentially be applied to LTBI screening and treatment. At the heart of successful ART initiation is assuring that patients accept their diagnosis, are motivated and ready to initiate treatment, 
and have social support [39]. Operational research has also highlighted the importance of designing a treatment regimen that fits into a patient's daily schedule and using reminder tools such as pill organizers [39]. Perhaps it is even more important to establish patient-provider rapport that is positive and free of judgment [39]. In our study, we observed that persons at high-risk of LTBI reactivation (i.e. young children, recent contacts, and those with immuno-suppressive conditions including HIV and diabetes) had a longer time to treatment default, compared to patients without these clinical risk factors. This may suggest an advantage to integrate effective risk communication within the overall LTBI care management. For example, close monitoring and counseling throughout the duration of LTBI therapy could enhance patient-provider communication and inform the best way to communicate the risk of progression to active disease to patients who otherwise do not perceive themselves at risk.

Our study has some limitations. We observed that treatment default occurred around day 30 of the nine-month daily INH regimen. In reality, the treatment default could have happened earlier; however, we were unable to measure the timing of treatment discontinuation more accurately. Indeed, INH monotherapy for LTBI is selfadministered, and clients are not required to bring back bottles for pill count, which prevents the assessment of the percentage of prescribed pills that were taken before treatment default. A client is recorded as lost to follow-up by the health unit only after they have missed their scheduled monthly clinic visit, which involves a medication refill and an evaluation for medication side effects. In addition, the co-morbidity risk factor data evaluated in this study, such as HIV co-infection and diabetes, are self-reported and likely suffer from underreporting bias. To evaluate the completeness of the data, we compare the prevalence of these two co-morbidities in a TB registry collected 20092015. Active TB is reportable by statute in the State of Florida [40]. In addition, the TB program reports all cases to the Centers for Disease Control and Prevention (CDC), using a report of verified case of tuberculosis (RVCT) [41]. In that population of 4,911 TB cases, HIV prevalence is $12.7 \%$ and diabetes prevalence is $11.7 \%$. These results suggest that these two co-morbidity risk factors are underreported in the LTBI dataset used in this study. In addition, it is possible that LTBI clients with HIV and diabetes are managed in the community by their primary care providers and are not reported to their county health departments because LTBI is not a reportable condition in Florida. Finally, these data were collected as part of LTBI treatment management and surveillance and not for research. As such, many important variables that could influence treatment default, such as patients' social support and patient-provider communication, were not measured. Future studies should take these factors and the limitations listed above into consideration.

\section{Conclusion}

In this analysis of INH treatment initiation data collected over 7 years in Florida, we see high levels of treatment discontinuation, with $17 \%$ of clients who initiated the nine-month daily regimen defaulting on therapy within the first 30 days. Because of data limitations, there are some uncertainties around the exact default time; however, it is possible these clients defaulted a lot sooner than recorded. Perhaps a universal approach to LTBI prevention efforts is not the solution to reach TB elimination by 2050 . Instead, we could look to enhance LTBI treatment adherence through innovative and holistic approaches that consider patients' understanding and awareness of LTBI, communicate the importance of treatment adherence, and remove social determinants of health that negatively influence health-seeking behaviors [42]. At the national level, strengthening connections between primary care providers and local health departments is crucial to accessing high-risk population groups and elevating LTBI treatment completion rates [43, 44]. Globally, with continued migration from high TB burden to low TB burden countries alike, international policies should reinforce systematic LTBI screening and management to support the End TB Strategy TB targets and TB elimination by $2050[4,45]$.

\section{Additional file}

Additional file 1: Supplementary Figures S1 - S3. (PDF 561 kb)

\section{Abbreviations}

3HP: Three-month Isoniazid and Rifapentine; 4R: Four-month rifampicin; ART: Antiretroviral therapy; CDC: Centers for Disease Prevention and Control; Cl: Confidence Interval; DOT: Directly Observed Therapy; FDOH: Florida Department of Health; HIV/AIDS: Human Immunodeficiency Virus/Acquired Immunodeficiency Syndrome; HR: Hazard Ratio; IGRA: Interferon gamma release assay; INH: Isoniazid; IRB: Institutional Review Board; LTBI: Latent tuberculosis infection; PHI: Protected Health Information; RVCT: Report of Verified Case of Tuberculosis; TB: Tuberculosis; TST: Tuberculin skin test; U.S.: United States

\section{Acknowledgements}

We gratefully acknowledge the contribution of the staff from the Florida Department of Health and the County Health Departments who collected the data used in this study.

\section{Authors' contributions}

MNS and ML, designed the study and directed its implementation; $H H, M N S$, $J A B, L$, and $Y Y$ conducted the analyses and interpreted the results; $L J$ collected the data; MNS and HJC drafted the first draft. All authors critically edited and approved the final draft before submission.

\section{Funding}

This work was supported by the NIH/NCATS Clinical and Translational Science Award to the University of Florida (KL2TR001429) and a Department of Medicine Gatorade start-up research grant (MNS). The funding organizations had no role in the design, conduct, collection, analysis, and interpretation of the data and no role in the preparation, review, or approval of the manuscript. 


\section{Availability of data and materials}

The data analyzed during the current study are not publicly available because they contain private health information (PHI) but are available from the corresponding author on reasonable request.

\section{Ethics approval and consent to participate}

Ethic approval for this study was granted by the Human Research Ethics Committee of the University of Florida and the Florida Department of Health (protocol 201700445). The study was a retrospective review of programmatic data and a waiver of informed consent was granted to retrospectively review these records.

\section{Consent for publication}

Not applicable.

\section{Competing interests}

The authors declare that they have no competing interests.

\section{Author details}

'Division of Infectious Diseases and Global Medicine, Department of Medicine, University of Florida, 2055 Mowry Road, Suite 250, Gainesville, FL 32611, USA. ${ }^{2}$ Emerging Pathogens Institute, University of Florida, 2055 Mowry Road, Gainesville, FL 32610, USA. 'Bureau of Communicable Diseases, Tuberculosis Control Section, Florida Department of Health, 4052 Bald Cypress Way, Tallahassee, FL 32399, USA. ${ }^{4}$ Department of Biostatistics, College of Public Health and Health Professions, University of Florida, 2055 Mowry Road, suite 250, Gainesville, FL 32610, USA.

\section{Received: 14 March 2019 Accepted: 21 August 2019}

\section{Published online: 03 September 2019}

\section{References}

1. Lönnroth K, Migliori GB, Abubakar I, D'Ambrosio L, de Vries G, Diel R, et al. Towards tuberculosis elimination: an action framework for low-incidence countries. Eur Respir J. 2015;45:928-52.

2. Zumla A, Raviglione M, Hafner R, von Reyn CF. Tuberculosis. N Engl J Med. 2013;368:745-55.

3. Ai J-W, Ruan Q-L, Liu Q-H, Zhang W-H. Updates on the risk factors for latent tuberculosis reactivation and their managements. Emerg Microbes Infect. 2016;5:e10.

4. World Health Organization. Implementing the end TB strategy: the essentials. http://www.who.int/tb/publications/2015/The_Essentials_to_End_ TB/en/. Accessed 28 Nov 2018.

5. LoBue PA, Mermin JH. Latent tuberculosis infection: the final frontier of tuberculosis elimination in the USA. Lancet Infect Dis. 2017;17: e327-33.

6. Stewart RJ, Tsang CA, Pratt RH, Price SF, Langer AJ. Tuberculosis - United States, 2017. MMWR Morb Mortal Wkly Rep. 2018;67:317-23.

7. Reves RR, Nolan CM. Tuberculosis Elimination in the United States: An Achievable Goal or an Illusion? Am J Respir Crit Care Med. 2012;186:i-iii.

8. Tsang CA, Langer AJ, Navin TR, Armstrong LR. Tuberculosis among foreignborn persons diagnosed $\geq 10$ years after arrival in the United States, 20102015. MMWR Morb Mortal Wkly Rep. 2017;66:295-8.

9. Bayer R, Castro KG. Tuberculosis elimination in the United States - the need for renewed action. N Engl J Med. 2017;377:1109-11.

10. Haas MK, Belknap RW. Updates in the treatment of active and latent tuberculosis. Semin Respir Crit Care Med. 2018;39:297-309.

11. Kim HW, Kim JS. Treatment of latent tuberculosis infection and its clinical efficacy. Tuberc Respir Dis. 2018;81:6-12.

12. Centers for Disease Control and Prevention. LTBI: A Guide for Primary Health Care Providers. Atlanta, USA: Division of Tuberculosis Elimination; 2018. https://www.cdc.gov/tb/publications/tbi/default.htm. Accessed 16 Oct 2018

13. Unissa AN, Subbian S, Hanna LE, Selvakumar N. Overview on mechanisms of isoniazid action and resistance in mycobacterium tuberculosis. Infect Genet Evol J Mol Epidemiol Evol Genet Infect Dis. 2016;45:474-92.

14. Gordin FM, Masur H. Current approaches to tuberculosis in the United States. JAMA. 2012;308:283-9.

15. Lardizabal A, Passannante M, Kojakali F, Hayden C, Reichman LB. Enhancement of treatment completion for latent tuberculosis infection with 4 months of rifampin. Chest. 2006;130:1712-7.
16. Cattamanchi A, Dantes RB, Metcalfe JZ, Jarlsberg LG, Grinsdale J, Kawamura LM, et al. Clinical characteristics and treatment outcomes of patients with isoniazid-monoresistant tuberculosis. Clin Infect Dis Off Publ Infect Dis Soc Am. 2009:48:179-85.

17. Page KR, Sifakis F, Montes de Oca R, Cronin WA, Doherty MC, Federline L, et al. Improved adherence and less toxicity with rifampin vs isoniazid for treatment of latent tuberculosis: a retrospective study. Arch Intern Med. 2006;166:1863-70

18. Saukkonen JJ, Cohn DL, Jasmer RM, Schenker S, Jereb JA, Nolan CM, et al. An official ATS statement: hepatotoxicity of antituberculosis therapy. Am J Respir Crit Care Med. 2006;174:935-52.

19. Chapman HJ, Lauzardo M. Advances in diagnosis and treatment of latent tuberculosis infection. J Am Board Fam Med JABFM. 2014;27:704-12.

20. Colson PW, Hirsch-Moverman Y, Bethel J, Vempaty P, Salcedo K, Wall K, et al. Acceptance of treatment for latent tuberculosis infection: prospective cohort study in the United States and Canada. Int J Tuberc Lung Dis Off J Int Union Tuberc Lung Dis. 2013.

21. Stuurman AL, Vonk Noordegraaf-Schouten M, van Kessel F, Oordt-Speets AM, Sandgren A, van der Werf MJ. Interventions for improving adherence to treatment for latent tuberculosis infection: a systematic review. BMC Infect Dis. 2016;16:257.

22. Menzies D, Long R, Trajman A, Dion M-J, Yang J, Al Jahdali H, et al. Adverse events with 4 months of rifampin therapy or 9 months of isoniazid therapy for latent tuberculosis infection: a randomized trial. Ann Intern Med. 2008; 149:689-97.

23. Moro RN, Borisov AS, Saukkonen J, Khan A, Sterling TR, Villarino ME, et al. Factors associated with noncompletion of latent tuberculosis infection treatment: experience from the PREVENT TB trial in the United States and Canada. Clin Infect Dis Off Publ Infect Dis Soc Am. 2016;62:1390-400.

24. Horsburgh CR, Goldberg S, Bethel J, Chen S, Colson PW, Hirsch-Moverman $Y$, et al. Latent TB infection treatment acceptance and completion in the United States and Canada. Chest. 2010;137:401-9.

25. McClintock AH, Eastment M, McKinney CM, Pitney CL, Narita M, Park DR, et al. Treatment completion for latent tuberculosis infection: a retrospective cohort study comparing 9 months of isoniazid, 4 months of rifampin and 3 months of isoniazid and rifapentine. BMC Infect Dis. 2017;17. https://doi. org/10.1186/s12879-017-2245-8

26. Glaziou P, Floyd K, Raviglione MC. Global epidemiology of tuberculosis. Semin Respir Crit Care Med. 2018:39:271-85.

27. Houben RMGJ, Dodd PJ. The global burden of latent tuberculosis infection: a re-estimation using mathematical modelling. PLoS Med. 2016;13: e1002152.

28. Mancuso JD, Diffenderfer JM, Ghassemieh BJ, Horne DJ, Kao T-C. The prevalence of latent tuberculosis infection in the United States. Am J Respir Crit Care Med. 2016:194:501-9.

29. Menzies NA, Cohen T, Hill AN, Yaesoubi R, Galer K, Wolf E, et al. Prospects for tuberculosis elimination in the United States: results of a transmission dynamic model. Am J Epidemiol. 2018;187:2011-20.

30. Horsburgh CR, Rubin EJ. Latent tuberculosis infection in the United States. N Engl J Med. 2011;364:1441-8.

31. Cain KP, Benoit SR, Winston CA, Mac Kenzie WR. Tuberculosis among foreign-born persons in the United States. JAMA. 2008;300:405-12.

32. Cain KP, Mac Kenzie WR. Overcoming the limits of tuberculosis prevention among foreign-born individuals: next steps toward eliminating tuberculosis. Clin Infect Dis. 2008:46:107-9.

33. Smieja MJ, Marchetti CA, Cook DJ, Smaill FM. Isoniazid for preventing tuberculosis in non-HIV infected persons. Cochrane Database Syst Rev. 2000:CD001363.

34. Eastment MC, McClintock AH, McKinney CM, Narita M, Molnar A. Factors that influence treatment completion for latent tuberculosis infection. J Am Board Fam Med. 2017;30:520-7.

35. Fiske $C T$, Yan F, Hirsch-Moverman Y, Sterling TR, Reichler MR. Risk factors for treatment default in close contacts with latent tuberculosis infection. Int J Tuberc Lung Dis Off J Int Union Tuberc Lung Dis. 2014;18:421-7.

36. CDC - Centers for Disease Control and Prevention. Treatment Regimens for Latent TB Infection. 2018. https://www.cdc.gov/tb/topic/treatment/tbi.htm. Accessed 28 Nov 2018.

37. Pease C, Hutton B, Yazdi F, Wolfe D, Hamel C, Quach P, et al. Efficacy and completion rates of rifapentine and isoniazid (3HP) compared to other treatment regimens for latent tuberculosis infection: a systematic review with network meta-analyses. BMC Infect Dis. 2017;17. https://doi.org/10.11 86/s12879-017-2377-x 
38. Assessment of the Safety, Tolerability, and Effectiveness of Rifapentine Given Daily for LTBI - Full Text View - ClinicalTrials.gov. https://clinicaltrials.gov/ct2/ show/NCT03474029. Accessed 9 Feb 2019.

39. Enriquez M, McKinsey DS. Strategies to improve HIV treatment adherence in developed countries: clinical management at the individual level. HIVAIDS Auckl NZ. 2011;3:45-51.

40. Florida Department of Health. TB Professionals Reporting Requirements. http://www.floridahealth.gov/diseases-and-conditions/tuberculosis/tbprofessionals/tb-report-require.html. Accessed 6 Jun 2019.

41. Centers for Disease Control and Prevention. Report of Verified Case of Tuberculosis (RVCT): Instruction Manual. USA; 2009. http://www.cdc.gov/tb/ programs/rvct/InstructionManual.pdf. Accessed 23 May 2016.

42. Hirsch-Moverman Y, Daftary A, Franks J, Colson PW. Adherence to treatment for latent tuberculosis infection: systematic review of studies in the US and Canada. Int J Tuberc Lung Dis Off J Int Union Tuberc Lung Dis. 2008;12: 1235-54.

43. Reves R, Daley CL. Screening for latent tuberculosis infection: a key step toward achieving tuberculosis elimination in the United States. JAMA Intern Med. 2016;176:1439-40.

44. Goswami ND, Gadkowski LB, Piedrahita C, Bissette D, Ahearn MA, Blain ML, et al. Predictors of latent tuberculosis treatment initiation and completion at a U.S. public health clinic: a prospective cohort study. BMC Public Health. 2012;12:468

45. Sotgiu G, Dara M, Centis R, Matteelli A, Solovic I, Gratziou C, et al. Breaking the barriers: Migrants and tuberculosis. Presse Medicale Paris Fr 1983. 2017; 462 Pt 2:e5-11.

\section{Publisher's Note}

Springer Nature remains neutral with regard to jurisdictional claims in published maps and institutional affiliations.

Ready to submit your research? Choose BMC and benefit from:

- fast, convenient online submission

- thorough peer review by experienced researchers in your field

- rapid publication on acceptance

- support for research data, including large and complex data types

- gold Open Access which fosters wider collaboration and increased citations

- maximum visibility for your research: over $100 \mathrm{M}$ website views per year

At BMC, research is always in progress.

Learn more biomedcentral.com/submissions 